\title{
Foam-Mat Drying Characteristics of Custard Apple Pulp
}

\author{
Krishna Deepa, Minati Mohapatra* \\ Department of Agricultural Processing and Food Engineering, College of Agricultural Engineering and Technology, Odisha University of \\ Agriculture and Technology, Bhubaneswar, India
}

Email address:

deepa.krish@gmail.com (K. Deepa),minati.agfe@gmail.com (M. Mohapatra)

${ }^{*}$ Corresponding author

\section{To cite this article:}

Krishna Deepa, Minati Mohapatra. Foam-Mat Drying Characteristics of Custard Apple Pulp. Journal of Food and Nutrition Sciences. Vol. 8, No. 4, 2019, pp. 89-95. doi: 10.11648/j.jfns.20200804.13

Received: June 22, 2019; Accepted: August 13, 2019; Published: July 13, 2020

\begin{abstract}
In the present study, foam mat drying of the custard apple pulp have been conducted by using Glycerol monostearate (GMS) $(0.5 \%, 1.5 \%, 2.5 \%, 3.5 \%$ and $4.5 \%)$ as foaming agent and $0.5 \%$ methyl cellulose (MC) as the stabilising agent with whipping time of 2, 4, 6, 8 and 10 minutes. Drying was carried out in a cabinet tray dryer at five different drying temperatures $(50,60$ and $70 \mathrm{C})$ with foam thickness of 2, 4 and $6 \mathrm{~mm}$. The optimum foaming conditions providing foam expansion of $(61.11 \%)$, foam stability $(94 \%)$ and lowest foam density $\left(0.60 \mathrm{gm} / \mathrm{cm}^{3}\right)$ was found to be $3.5 \%$ GMS with $0.5 \%$ methyl cellulose whipped for 6 minutes. The tray drying of foamed pulp took 240-450 minutes whereas the non-foamed pulp took 420 to 450 minutes saving about 180-240 minutes drying time. Among all the parameters studied, the combination of $3.5 \%$ GMS and $0.5 \%$ methyl cellulose whipped for 6 min dried at $60 \mathrm{C}$ with foam thickness of $4 \mathrm{~mm}$ was found to be the best treatment for custard apple powder preparation.
\end{abstract}

Keywords: Custard Apple, Drying, Foam Mat Drying, Foaming, Drying Characteristics

\section{Introduction}

Custard apple (Annona squamosa) is a tropical fruit, coming under the Annonaceae family, is highly nutritious fruit, packed with vitamin $\mathrm{C}$, vitamin $\mathrm{A}$, Vitamin $\mathrm{B}_{6}$, magnesium, potassium, copper and plenty of dietary fibres. It is beneficial for cardiac disease, diabetes, hyperthyroidism and cancer. The ripe fruits of custard apple are applied to malignant tumors to hasten suppuration. The fruit pulp due to its richness in free sugars, minerals and vitamins is known to serve as blood tonic [1]. Custard apple pulp has been recognized as a base ingredient in various food products like ice cream, milk shakes, beverages due to its characteristics taste and flavour $[2,3]$. The flavour components of fresh pulp are due to the volatile compounds of terpenes namely $\alpha$ pinene, $\beta$-pinene, linalool, germacrene-D and spathulenol, Benzyl alcohol etc [4].

Custard apples are perishable and cold storage is not promising because of the development of an unattractive brown colouration on the skin which decreases the market value [5]. Custard apple gives excessive production during the season, very often perishes owing to inadequate preservation techniques. The pulp when exposed to air undergoes discolouration due to polyphenol oxidase activity. Discolouration occurs during storage in frozen state and continues throughout thawing and causes loss of quality and value [6]. Therefore, storage of either fresh custard apple fruit or fruit pulp or concentrate in ambient or refrigeration condition is a limitation due to these mentioned problems.

Drying is an age longed preservation technique which can not only increase the shelf life of the product but also makes the product available throughout the year even in the off seasons. Production of dried powder from custard apple pulp by drying is a possible solution for making use of this underutilized fruit. But, due to the presence of high sugar content, drying is not achieved properly and making it difficult to reach to the end point and quality aspects are a major concern.

Generally, pulpy fruits like mango, pineapple, custard apple etc. are difficult to dry for powder as they contain a large amount of sugar content, dense physical as well as chemical structure. The stickiness and caking properties cause a lot of difficulty in drying. Simple hot air drying is not very promising as it is slow and induce colour and flavor change in the final product rejecting its quality for export 
potential. Fruit pulps are generally spray dried or drum dried, but, in no cases it becomes cheaper for drying. Therefore, drying alternatives could be suggested for fruit pulps for making powder. Foam mat drying by principle can increase the surface area for drying due to foaming. This helps in making the fruit pulp more porous, thus allowing rapid moisture removal with a higher drying rate. Foam mat drying is a process in which a liquid or semi solid material is converted into stable foam by incorporating substantial volume of air or other inert gases in the presence of foaming and stabilising agents. The foaming agent works as a foam inducer and/or stabilizer. The foam thus formed is then spread as a thin mat or sheet and allowed to go for drying until it is dried upto the required moisture levels. The dehydrated product is then allowed to go for conditioning and converted into powder form. Many experiments have been done on foam mat drying of different products like mango [7, 8] star fruit [9], banana [10], tamarind [11], papaya [12], malta juice [13] stone apple [14] and soymilk [15] etc. No works has been suggested till now for foaming of custard apple pulp and then subsequent drying in a thin mat in convection dryer. Present investigation has been taken to study the foaming behavior of custard apple pulp for drying and effects of foaming and non-foaming on drying characteristics.

\section{Materials and Methods}

Fresh Custard apples of uniform sizes and maturity were brought from the local Market of Bhubaneswar. The initial moisture content, pulp percentage, TSS and bulk density of the custard apple pulp were found to be $74-76 \%$ (w.b), 35$45 \%, 23{ }^{0} \mathrm{~B}$ and $1.090 \mathrm{~g} / \mathrm{cm}^{3}$ respectively. Moisture content of the custard apple pulp was determined with the help of the hot air oven method following the standard procedure ${ }^{15}$.

\subsection{Foaming of Custard Apple Pulp}

The custard apple pulp extracted was blended in a house hold mixer (Summit make) and taken for foaming. Foaming was carried out by using Glycerol monostearate (GMS) as foaming agent at five different levels $0.5,1.5,2.5,3.5$ and $4.5 \%(\mathrm{w} / \mathrm{w})$ and $0.5 \%$ methyl cellulose as stabilising agent. A domestic hand blender (ORPAT, HHB-100E) operating at $18,000 \mathrm{rpm}$ was used for incorporating air into the sample and causing foaming. Initially, in priliminary experiments, foaming was not achieved in custard apple pulp due to high TSS content $\left(23^{0} \mathrm{~B}\right)$. Then, pulp was diluted with distilled water at $1: 1,1: 2,1: 3$ and $1: 4$ pulp/water ratio (by weight). It was afterwards standardized as to take pulp to water ratio as $1: 2$, as it gave maximum expansion of foams compared to other ratios. The final TSS content of the pulp was $6.8^{0} \mathrm{~B}$.

\subsection{Determination of Foaming Parameters}

Calculated amount of the custard apple pulp, Glycerol monostearate (GMS) and methyl cellulose were taken in measuring beaker. Foaming was done for five different whipping times of 2, 4, 6, 8 and 10 minutes. The different foaming parameters determined were foam expansion, foam stability and foam density [8, 14] using equations 1 to 3 .

$$
\begin{gathered}
\text { Foam Expansion }(\mathrm{FE})=\left[\frac{\mathrm{V}_{1}-\mathrm{V}_{0}}{\mathrm{~V}_{0}}\right] \times 100 \\
\text { Foam stability }=\mathrm{V}_{0} \frac{\Delta \mathrm{t}}{\Delta \mathrm{V}} \\
\text { Foam density }\left(\mathrm{g} / \mathrm{cm}^{3}\right)==\rho \frac{\mathrm{v}_{0}}{\mathrm{~V}_{1}}
\end{gathered}
$$

Where, $V_{0}$ is the initial volume of the custard apple pulp before foaming $(\mathrm{ml})$ and $V_{1}$ is the final volume of the custard apple pulp after foaming $(\mathrm{ml}), \Delta \mathrm{V}$ is the decrease in the volume of the pulp in a time interval of $\Delta \mathrm{t}, \rho$ is the density of the pulp.

Foam expansion is expressed as the percentage increase of the volume of the pulp after foaming. Foam stability was estimated indirectly by observing the reduction of foam volume in a glass tube (Figure 1) by taking $50 \mathrm{ml}$ of foamed pulp in it and kept for settling for 3 hours. The decrease of the foam volume was noted at every $30 \mathrm{~min}$. time interval.

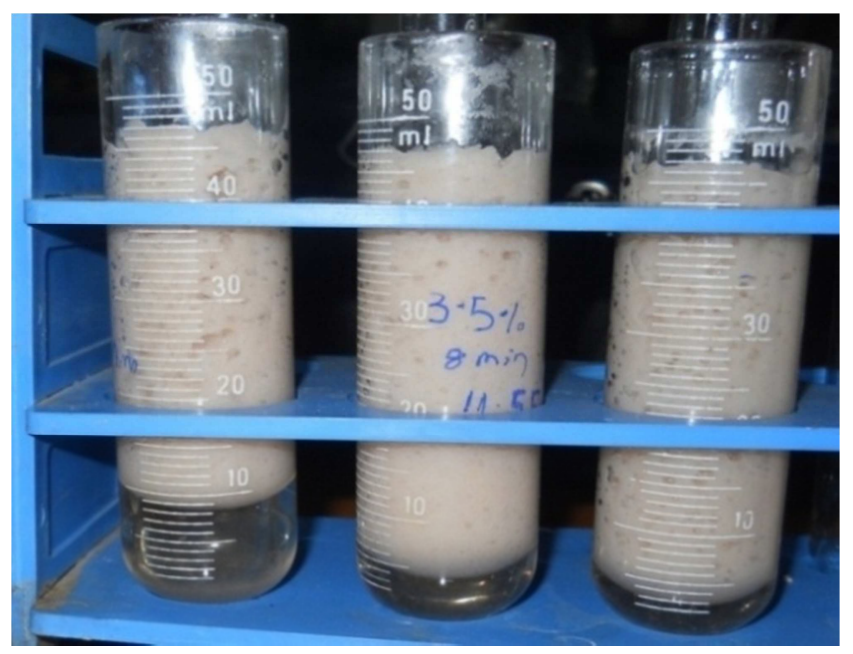

Figure 1. Determination of foam stability of the foamed custard apple pulp.

\subsection{Drying of the Foamed Custard Apple Pulp}

Drying experiments were performed in laboratory scale cabinet tray dryer after foaming of the custard apple pulp was done. The foamed pulp were uniformly spread over a circular steel plate of dimension $27.8 \times 27.8 \times 5 \mathrm{~cm}$ and kept for drying in a tray dryer. For the drying experiments, different levels of drying temperatures were set i.e. $50,55,60,65$ and $70^{\circ} \mathrm{C}$. The different levels of foam thicknesses were maintained as $2,4,6$, 8 and $10 \mathrm{~mm}$. The foamed pulp was taken in the stainless steel plate and allowed to spread in the required thickness marked before. Air velocity was kept at a constant value of $1.0 \mathrm{~m} / \mathrm{s}$ with an accuracy of $\pm 0.03 \mathrm{~m} / \mathrm{s}$ for all drying experiments, measured with a Testo 440 Vane Probe anemometer and flowed perpendicular to the bed. The loss of weight of the samples after drying were recorded for every 10 minutes duration for the first 1 hour and then after 15 and 30 minutes. Drying was carried out up to three consecutive constant weight 
of the sample was recorded. From the weight loss data, moisture content and drying rate were calculated.

\section{Results and Discussion}

\subsection{Effect of GMS Concentration and Whipping Time on Foam Expansion}

The variation of foam expansion at different concentrations of GMS and time of whipping is shown in Table 1. In $0.5 \%$ GMS treated sample there was no increase of the foaming volume as whipping time was varied, resulting into no foam expansion. In all other GMS treatments, the foam expansion values were increased with increase of the GMS concentration. The foam expansion also increased with whipping duration up to a time period of 4-6 minute but after that, there was a stable trend was found up to 10 minutes of foaming (Figure 2). This type of phenomena may be observed due to the present mixer condition which operates at a fixed rpm of 18000 . Some amount of foaming may be collapsed due to overheating, caused due to overrated operation of the blender.

Glycerol monostearate at $0.5 \%$ level recorded the lowest foam expansion value of $11 \%$ in all of its foaming durations, suggesting that GMS of $0.5 \%$ was not sufficient to induce foaming in the pulp. With increasing GMS concentration from 1.5 to $4.5 \%$ by weight the foam expansion value increased. Glycerol monostearate level at $3.5 \%$ and $4.5 \%$ by weight recorded higher foam expansion values of $61.11 \%$ and $72.22 \%$ respectively for whipping duration of 6 minute. The increase in foam expansion from 0.5 to $1.5 \%$ and 1.5 to $2.5 \%$ GMS for different whipping time gave significant $(\mathrm{p}<0.05)$ different values, but the rise from 3.5 to $4.5 \%$ GMS was not significant $(\mathrm{P}<0.05)$. It was therefore evident that maintaining 2.5\% GMS level with 6 minute whipping time will be optimum for obtaining foaming in custard apple pulp for subsequent drying experiments. Similar findings were also observed by Jaya and Das (2004) for mango powder preparation with optimum requirement of TCP and GMS as $0.015 \mathrm{~kg}$ per $\mathrm{kg}$ mango solid for foaming. The optimum concentrations of foaming agent for Alphonso mango pulp were determined to be $1 \%$ soy protein, $2 \%$ glycerol monostearate, and $10 \%$ egg albumen after 25 min whipping time. Optimum level of GMS (3.10 g/100 g pulp), Methyl cellulose (0.32 g/100 g pulp), Pulp Concentration (13.2Bx) and Whipping time of $2 \mathrm{~min}$ was found best for bael powder [14].

Table 1. Effect of GMS concentration (\%) and whipping time (min) on foam expansion (FE).

\begin{tabular}{|c|c|c|c|c|c|}
\hline \multirow{2}{*}{ Whipping Time (min) } & \multicolumn{5}{|c|}{ Foam Expansion (\%) } \\
\hline & GMS $0.5 \%)$ & GMS (1.5\%) & GMS (2.5\%) & GMS (3.5\%) & GMS (4.5\%) \\
\hline 2 & 11 & 33.33 & 38.89 & 55.56 & 61.11 \\
\hline 4 & 11 & 34.44 & 41.11 & 60.56 & 61.11 \\
\hline 6 & 11 & 49.44 & 52.22 & 61.11 & 72.22 \\
\hline 8 & 11 & 49.89 & 55.56 & 60.89 & 66.67 \\
\hline 10 & 11 & 50.00 & 54.44 & 58.89 & 61.11 \\
\hline Paired T-value & - & $3.80^{\mathrm{ab}}$ & $4.06^{\mathrm{bc}}$ & $2.48^{\mathrm{cd}}$ & $2.06^{\mathrm{de}}$ \\
\hline p-value & & $0.019^{* *}$ & $0.015^{* *}$ & $0.054^{\mathrm{ns}}$ & $0.108^{\mathrm{ns}}$ \\
\hline
\end{tabular}

$\mathrm{ab}=$ between $0.5 \& 1.5 \%$ GMS, $\mathrm{bc}=$ between $1.5 \& 2.5 \% \mathrm{GMS}, \mathrm{cd}=$ between $2.5 \& 3.5 \%$, de= between $3.5 \& 4.5 \%$

\subsection{Effect of GMS Concentration and Whipping Time on Foam Density}

The density of the custard apple pulp foam was ranged between 0.60 to $0.94 \mathrm{~g} / \mathrm{cm}^{3}$ (Table 2). The highest foam density value of $0.94 \mathrm{gm} / \mathrm{cm}^{3}$ was recorded for GMS at a level of $0.5 \% \mathrm{w} / \mathrm{w}$. The lowest foam density value of 0.60 $\mathrm{gm} / \mathrm{cm}^{3}$ was recorded for GMS at level of $4.5 \%$ for a whipping duration of $6 \mathrm{~min}$. The density of the foam at $2.5 \%$ GMS and above 6 minutes of whipping duration was 0.67 $0.68 \mathrm{~g} / \mathrm{cm}^{3}$. Therefore, as per desired, low density foam were obtained between 2.5 to $4.5 \%$ GMS for 6-8 whipping time.

Table 2. Variation of Foam density with GMS concentration and whipping time.

\begin{tabular}{lllll}
\hline \multirow{2}{*}{ Whipping time (min) } & \multicolumn{2}{l}{ Foam density $\left(\mathbf{g} / \mathbf{c m}^{\mathbf{3}}\right)$} & & \\
\cline { 2 - 5 } & $\mathbf{0 . 5 \%}$ GMS & $\mathbf{1 . 5 \%}$ GMS & $\mathbf{2 . 5 \%}$ GMS & $\mathbf{3 . 5 \%}$ GMS \\
\hline 2 & 0.94 & 0.78 & 0.75 & 0.67 \\
4 & 0.94 & 0.77 & 0.74 & 0.65 \\
6 & 0.94 & 0.69 & 0.68 & 0.65 \\
8 & 0.94 & 0.69 & 0.67 & 0.65 \\
10 & 0.94 & 0.69 & 0.67 & 0.60 \\
\hline
\end{tabular}

\subsection{Effect of GMS Concentration and Whipping Time on Foam Stability}

Foam stability of custard apple pulp foamed at different GMS level and whipping time were conducted for a maximum holding time period of 3 hour i.e. 180 minute. With the increase of the standing time foam stability value decreased for $0.5 \%$ GMS. It was evident from figure 2 that, there was small difference of foam stability values between 0.5 and $1.5 \%$ GMS treated samples after $180 \mathrm{~min}$. But there was a larger difference in foam stability values were observed between $1.5 \%$ to $2.5 \%, 3.5 \%$ and $4.5 \%$ GMS treated sample. The foam stability value of $2.5 \%$ GMS treated sample was found out to be $1.64 \%$ more than that of 
the $1.5 \%$ GMS treated samples after $180 \mathrm{~min}$. But between $2.5 \%$ and $3.5 \%$ samples, the difference was only $0.2 \% .2 .5 \%$ GMS treated sample whipped for $6 \mathrm{~min}$ as the best sample considering foam stability value. Similar research finding for papaya pulp suggest forming by incorporating methyl cellulose as foaming agent at different concentrations 0.25 , $0.50,0.75$ and $1.00 \%$ on $\mathrm{w} / \mathrm{w}$ basis gave most stable foam formation as $83 \%$ at $0.75 \%$ methyl cellulose with $9{ }^{0} \mathrm{~B}$ pulp and whipping time of $15 \mathrm{~min}$ [12].

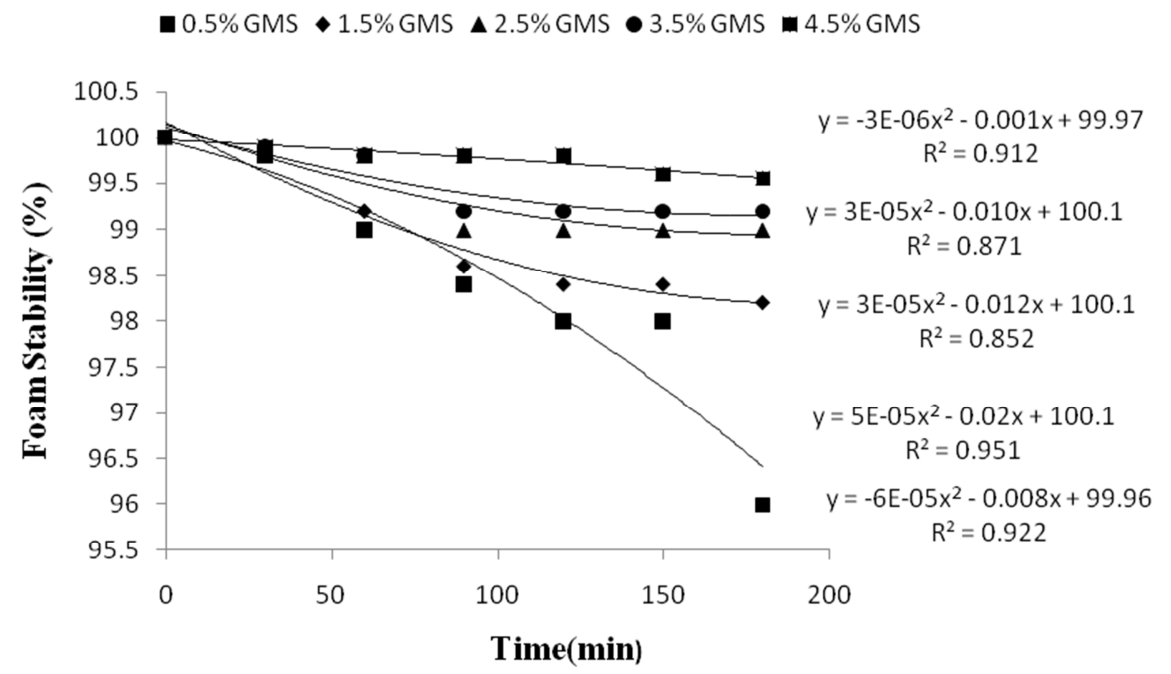

Figure 2. Foam stability of custard apple pulp at different GMS concentrations.

\subsection{Drying Characteristics of Custard Apple Pulp}

\subsubsection{Effect of Drying Air Temperature and Foam Thickness on Drying Time}

The variations of the moisture content of foamed custard apple pulp (with $2.5 \%$ GMS and $0.5 \%$ methyl cellulose) with drying time at different air temperature $\left(50,60,70^{\circ} \mathrm{C}\right)$ and foam thickness $(2,4,6 \mathrm{~mm})$ were presented in Figures 3 and 4 respectively. Moisture content of the samples decreased with the drying time. The total drying time required to achieve up to a constant moisture level was found to be 720 min, $600 \mathrm{~min}$ and $330 \mathrm{~min}$ for 50, 60, $70 \mathrm{C}$ drying air temperature respectively. So to get nearly the same amount of the moisture removal, the time differences between 50 and 60 $\mathrm{C}, 60$ and $70 \mathrm{C}$ and 50 and $70 \mathrm{C}$ dried sample were found to be $120 \mathrm{~min}, 270 \mathrm{~min}$ and $390 \mathrm{~min}$ respectively. At higher drying temperature i.e $70 \mathrm{C}$ the drying time was less as compared to lower temperature levels. It is in accordance with research findings [7, 12] for other type of fruit pulps like mango or papaya.

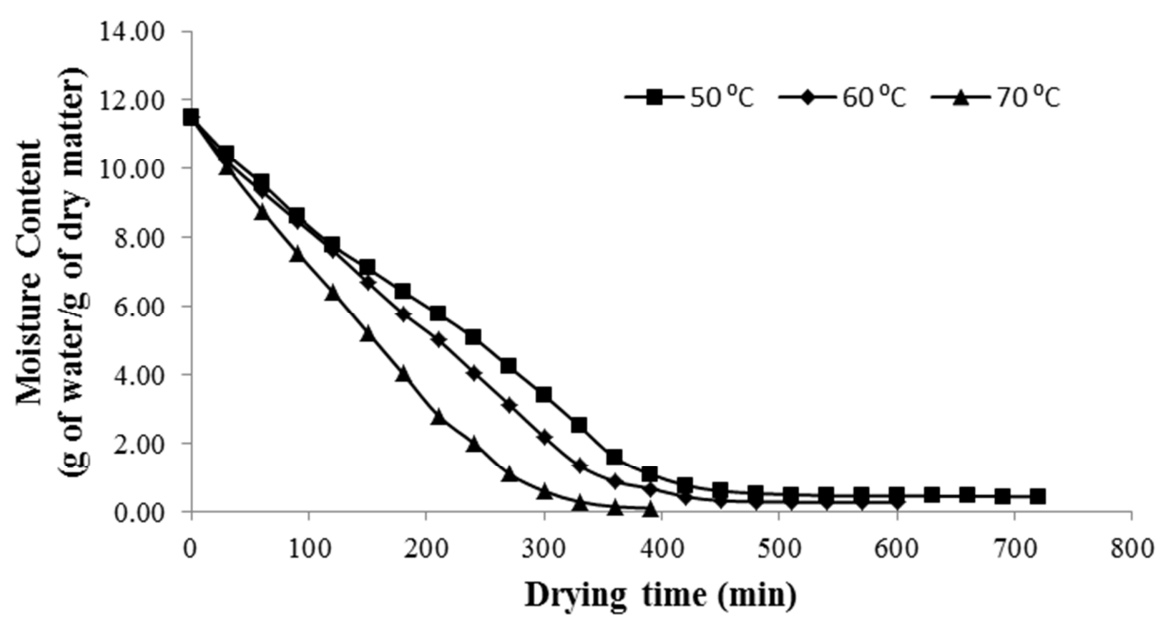

Figure 3. Drying curve of foamed custard apple pulp at different drying air temperature.

The relationship between the moisture content and drying time for various foam thicknesses $(2 \mathrm{~mm}, 4 \mathrm{~mm}, 6 \mathrm{~mm})$ at $2.5 \%$ GMS treated 4 minute whipped and $60 \mathrm{C}$ dried sample values was presented in Figure 4. It showed with the increase of the foam thickness from 2 to $6 \mathrm{~mm}$, there was an increase of the drying time. The drying time required to get desired final moisture content for $2 \mathrm{~mm}$ pulp thickness was 360 minute, whereas it was $600 \mathrm{~min}$ for $4 \mathrm{~mm}$ pulp and 690 minutes for $6 \mathrm{~mm}$ thickness of pulp. As expected the more thickness foamed sample took more drying time than the 
lower thickness samples. Similar findings were also reported by other authors [7].

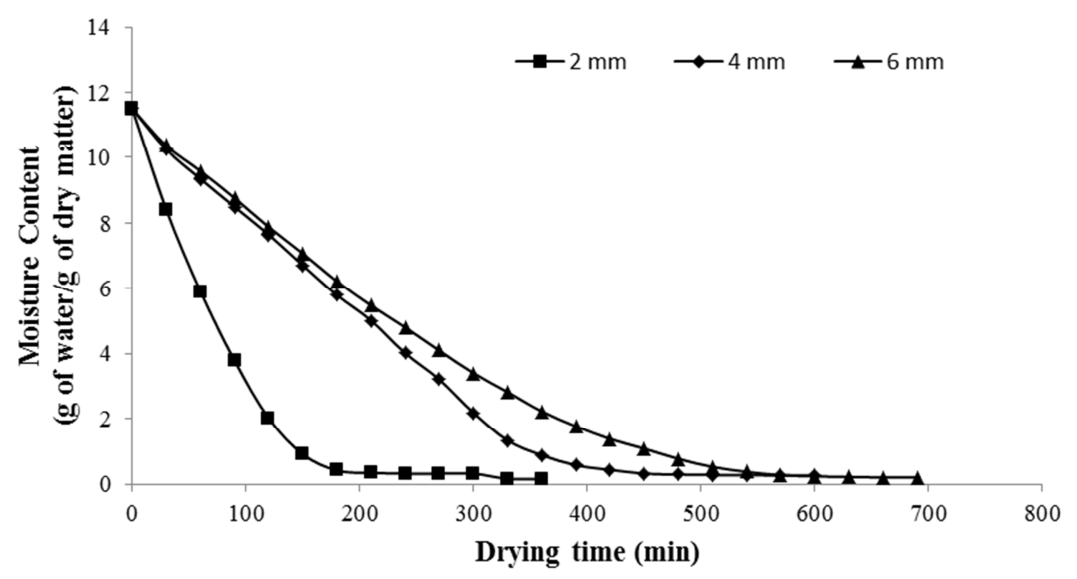

Figure 4. Drying curve of foamed custard apple pulp at different foam thickness.

\subsubsection{Effect of Drying Temperature and Foam Thickness on Variation of Drying Rate}

The drying rate curves for custard apple pulp as a function of moisture content at different drying air temperatures and drying foam thickness were shown in figures 5 and 6 respectively. The drying rate was calculated from the drying data by estimating the change in the moisture content, which occurred in each time interval and was expressed as $g$ of water/ $\mathrm{g}$ of dry matter $/ \mathrm{h}$. The drying rates were higher at the beginning of the drying process because the moisture was present in abundance at the surface of the product. The drying rates decreased as drying progressed further. The increased drying air temperature also affected drying rate in all drying conditions. Increase in drying air temperature increased the drying rates, reducing drying time. Such trends have also been reported for mango ${ }^{7}$. For instance, drying rate curve for custard apple sample treated with $2.5 \%$ GMS whipped for 4 minute of $3 \mathrm{~mm}$ of pulp thickness at different drying air temperatures showed that the drying rates values were $2.09,2.5$ and $2.85 \mathrm{~g}$ of water/g of dry matter/h at 50,60 and $70 \mathrm{C}$ respectively with a moisture content value of $11.50 \mathrm{~g}$ of water/g of dry matter. But with the decrease of the moisture content value the corresponding drying rates values also decreased.

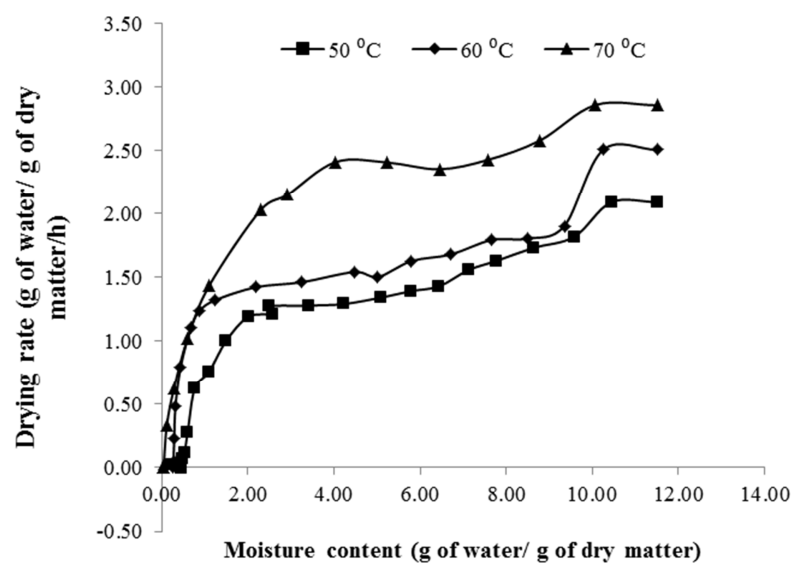

Figure 5. Drying rate curve of foamed custard apple pulp at different drying air temperature.
Similar types of results were also found for drying rate at different foam thickness. The drying rate curve of $2.5 \%$ GMS treated sample whipped for $4 \mathrm{~min}$ at $60^{\circ} \mathrm{C}$ drying temperature was presented in Figure 8. The initial drying rates values were $6.18,2.5,2.27 \mathrm{~g}$ of water/g of dry matter/h with an initial moisture level of $11.5 \mathrm{~g}$ of water/g of dry matter for $2 \mathrm{~mm}, 4 \mathrm{~mm}$ and $6 \mathrm{~mm}$ drying thicknesses values respectively. But with the decrease of the moisture values, there was a decrease of the drying rate values was observed.

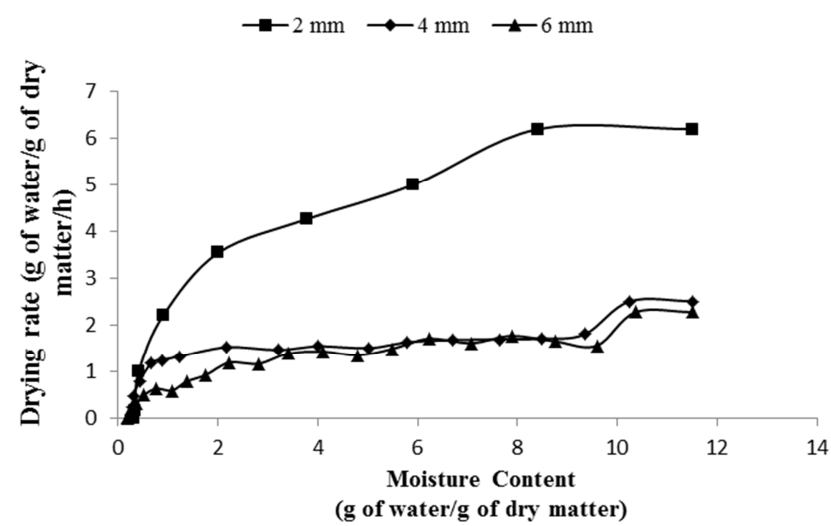

Figure 6. Drying rate curve of foamed custard apple pulp at different foam thickness.

Increasing the drying air temperature in foam mat drying of custard apple pulp from 50 to $70^{\circ} \mathrm{C}$ reduced the drying time from 720 minutes to 420 minutes saving around 300 minutes drying time. The foam thickness has similar effects showing less time (360 $\mathrm{min}$ ) for $2 \mathrm{~mm}$ thickness than $6 \mathrm{~mm}$ thickness (690 $\mathrm{min})$.

\subsubsection{Effect of Drying Temperatures and Thickness on Moisture Diffusivity}

The moisture diffusivity value increased with increasing drying air temperature giving range of $1.53 \times 10^{-8}-7.62 \times$ $10^{-7}$ for $70^{\circ} \mathrm{C}$ with average $D_{\text {eff }}$ as $2.225 \times 10^{-7}$. Similarly with reducing the foam layer thickness from 6 to $2 \mathrm{~mm}$ the average $D_{\text {eff }}$ value increased from $2.8 \times 10^{-8}$ to $3.71 \times 10^{-6}$. 
Table 3. Moisture diffusivity, average moisture diffusivity and drying time at different temperature and foam thickness.

\begin{tabular}{lllll}
\hline Variables & & Drying time $(\mathbf{m i n})$ & Moisture diffusivity $\left(\mathbf{m}^{2} / \mathbf{s}\right)$ & Average Diffusivity $\left(\mathbf{m}^{2} / \mathbf{s}\right)$ \\
\hline \multirow{2}{*}{ Temperature $\left({ }^{\circ} \mathrm{C}\right)$} & 50 & 720 & $5.61 \times 10^{-9}-7.46 \times 10^{-9}$ & $1.6 \times 10^{-9}$ \\
& 60 & 600 & $1.81 \times 10^{-8}-8.10 \times 10^{-8}$ & $2.30 \times 10^{-8}$ \\
& 70 & 420 & $1.53 \times 10^{-8}-7.62 \times 10^{-7}$ & $2.225 \times 10^{-7}$ \\
Foam thickness (mm) & 2 & 360 & $3.36 \times 10^{-7}-7.96 \times 10^{-6}$ & $3.71 \times 10^{-6}$ \\
& 4 & 600 & $1.81 \times 10^{-8}-8.10 \times 10^{-8}$ & $2.30 \times 10^{-8}$ \\
\hline
\end{tabular}

\subsubsection{Effect of Foaming and Non-Foaming on Drying Time and Drying Rate of Custard Apple Pulp}

The time taken by the foamed pulp from a moisture content of 3.17 to $0.16 \mathrm{~g}$ of water/g of dry matter was found to be 900 minutes and the time taken by the foamed pulp from 3.17 to $0.16 \mathrm{~g}$ of water/ $\mathrm{g}$ of dry matter was found to be 570 minutes (Figure 7). So, the extra time taken by the non foamed pulp was found to be 330 minute.

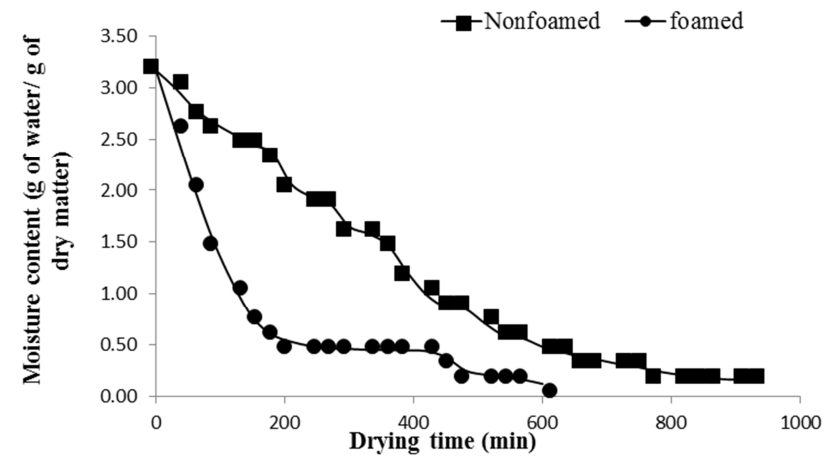

Figure 7. Drying curve of foamed and non-foamed custard apple pulp.

There was a decreasing trends of the drying rate was observed in both of the foamed and non foamed pulp with the decrease of the moisture content (Figure 8). The drying rate value decreased from 1.75 to 0.75 in non foamed pulp and 2.09 to $1.01 \mathrm{~g}$ of water/ $\mathrm{g}$ of dry matter/ $\mathrm{h}$ in foamed pulp. So, the drying rate values were higher for foamed pulp than that of the non-foamed custard apple pulp.

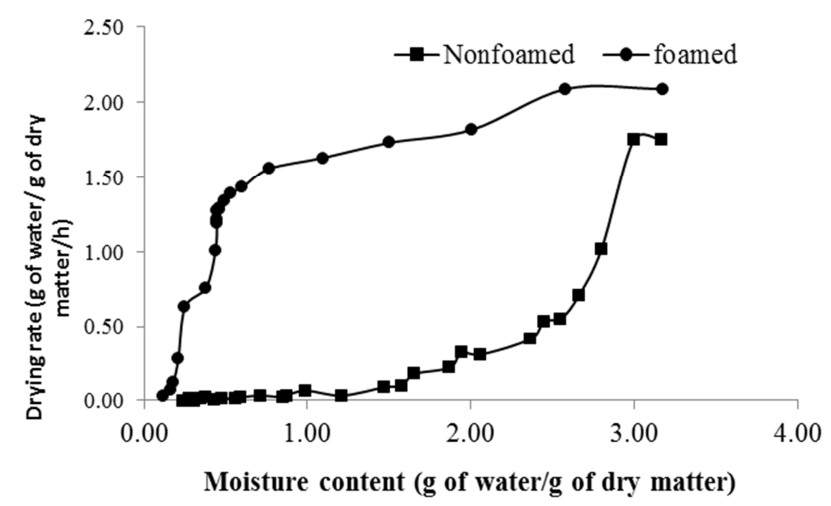

Figure 8. Drying rate curve of foamed and non-foamed custard apple pulp.

\section{Conclusion}

Custard apple (Annona squamosa) is a tropical fruit, packed with carbohydrates, vitamin $\mathrm{C}$, vitamin $\mathrm{A}$, Vitamin $\mathrm{B}_{6}$, magnesium, potassium, copper and plenty of dietary fibres. It is beneficial for cardiac disease, diabetes, hyperthyroidism and others. Preparation of dried powder of custard apple will be beneficial to use in different food formulations and more importantly can beat the seasonal unavailability and make it available whenever as desired. Foam mat drying is a cheaper method of producing good quality fruit pulp powder. Therefore, foam mat drying characteristics of custard apple pulp was evaluated taking Glycerol monostearate $(0.5 \%, 1.5 \%$, $2.5 \%, 3.5 \%$ and $4.5 \%$ ) as foaming agent and $0.5 \%$ methyl cellulose as the stabilising agent at different whipping time i.e. 2, 4, 6, 8 and 10 minutes. Drying of foamed pulp were undertaken in a cabinet tray dryer at three different drying temperatures $\left(50,60\right.$ and $\left.70^{\circ} \mathrm{C}\right)$ and foam thickness of 2,4 , and $6 \mathrm{~mm}$. The optimum foaming conditions providing highest foam expansion $(61.11 \%)$, foam stability (94\%) and lowest foam density $\left(0.67 \mathrm{gm} / \mathrm{cm}^{3}\right)$ of custard apple pulp was found at $3.5 \%$ GMS, $0.5 \%$ methyl cellulose whipped for 6 minutes. The tray drying of foamed pulp took 240-450 minutes whereas the non-foamed pulp took 420 to 450 minutes saving about 180240 minutes of drying time. Among all the parameters studied, the combination of $3.5 \%$ GMS, $0.5 \%$ methyl cellulose whipped for 6 min dried at $60 \mathrm{C}$ with foam thickness of $4 \mathrm{~mm}$ was found to be the best treatment for obtaining custard apple powder.

\section{References}

[1] Rao, S. N. 1974. Annonas-The legendary fruit. Indian Horticulture 19 (3): 19-21.

[2] Khurdiya, D. S. 2001. Post harvest management of underutilized fruits for fresh marketing. Winter school on exploitation of underutilized fruits. Division of Post Harvest Technology. IARI, New Delhi: 266-274.

[3] Hasmi, S. I. and Pawar, V. N. 2011. Studies on physical and chemical characteristics of custard apple fruit pulp from different location. Journal of Dairying and Food, 31 (2): 117 - 120.

[4] Shashirekha, M. N., Rajarathnam, S., Vijayalakshmi, M. R., Revathy, B. 2003. A process for the preparation of jelly from custard apple. PCT patent application no. PCT0434.

[5] Purohit, A. G., Salunkhe, D. K., Kadam, S. S. 1995. Annonaceous fruits. Hand book of Fruit Science and Technology: 377-385.

[6] Pardede, E., Buckle, K. A., Srzednicki, G. 1994. Control of browning during thawing of custard apple pulp. Food Australia 46 (5): 205-206. 
[7] Rajkumar, P., Kailappan, R., Viswanathan, R., Raghavan, G. S. V. 2007. Foam mat drying of Alphonso mango pulp. Drying Technology, 25: 357-365.

[8] Jaya, S., Das, H. 2009. Glass transition and sticky point temperatures and stability/mobility diagram of fruit powders. Food and Bioprocess Technology, 2 (1): 89-95.

[9] Karim, A. A., Wai, C. C. 1999. Foam-mat drying of starfruit puree. Stability and air drying characteristics. Food Chemistry 64 (3): $337-343$.

[10] Sankat, C. K.; Castaigne, F. Foaming and drying behaviour of ripe bananas. 2004. Lebensmittel-Wissenschaft Technologie, 37 (5), $517-525$.

[11] Eduardo, J. V. C., Espinosa, P. G., Beristain, C. I., Tehuitzil H. R. 2001. Effect of foaming agents on the stability, rheological properties, drying kinetics and flavour retention of tamarind foam-mats. Food Research International, 34 (7): 587-598.

[12] Kandasamy, P., Varadharaju, N., Kalemullah, S., Moitra 2012.
Production of papaya powder under foam mat drying using methyl cellulose as foaming agent. Asian Journal of Food Agriculture Industries, 5 (5): 374-387.

[13] Khan, C., Pandey, R. K. 2012. Optimization of foam mat drying process variables for malta powder. International Journal of Food, Agriculture and Veterinary Sciences 2 (2): pp. 67-73.

[14] Bag, S. K., Srivastav, P. P., Mishra, H. N. 2009. Optimization of process parameters for foaming of Bael (Aegle marmelos L.) fruit pulp. Food Bioprocess Technology, 4: 1450-1458.

[15] Akintoye, O. A. and Oguntund, A. O. 1991. Preliminary investigation on the effect of foam stabilizers on the physical characteristics and reconstitution properties of foam mat dried soymilk. Drying Technology: An International Journal, 9 (1): 245-262.

[16] AOAC (Association of Analytical Chemist) 1995. Official Methods of Analysis, $15^{\text {th }}$ Edition. Washington, D. C., USA: 69-88. 